\title{
The Value Of Growth At A Reasonable Price: Evidence From The Taiwan Stock Exchange
}

Kathleen Hodnett, PhD, University of the Western Cape, South Africa Heng-Hsing Hsieh, PhD, CFA, University of the Western Cape, South Africa

\begin{abstract}
Value and growth represent two opposite investment styles when price multiples such as the priceto-earnings ratio and the price-to-market ratio are used to classify the investment styles of equities. Motivated by the argument of Peters (1991) and Broussard, Michayluk and Needy (2005) that price multiples are imperfect valuation measures for firms other than firms in mature industries, and also the argument of Ahmed and Nanda (2001) that value and growth investing strategies should not be mutually exclusive, this study attempts to identify stocks with aboveaverage sales growth that trade at average or below-average price-to-sales multiples. Their performance relative to pure growth portfolios is subsequently analyzed. Using variants of historical growth rates relative to previous month, previous year, historical low and historical high as measures of growth potential, and the price-to-sales multiple as the measure of the reasonableness of the stock prices, we construct growth-at-a-reasonable-price (GARP) portfolios on the Taiwan Stock Exchange over the period from 01 January 2000 through 31 March 2010. Study results indicate that the GARP portfolios outperform their counterpart pure growth portfolios over the examination period. The incremental contributions of GARP measured in terms of the return improvements, risk reduction and improvements in the Sharpe ratios when switching from the pure growth stock selection technique to the GARP selection technique, is found to be significant over the examination period.
\end{abstract}

Keywords: Style Anomalies; Value Stocks; Growth Stocks; Growth-At-A-Reasonable-Price (GARP); Stock Selection; Taiwan Stock Exchange

\section{INTRODUCTION}<smiles>[C]1C=CCC=C1</smiles>
alue and growth are two opposite investment styles. Investors who invest in value stocks believe that the stocks are temporarily underpriced by the market and are willing to hold on to these stocks until their potentials are realized. Growth stocks, on the other hand, are those companies that have high growth potential in their sales and earnings and are generally highly priced by market investors. The debate between value and growth investment styles begins with the value anomaly documented by Basu (1977). Using the price-toearnings multiple as a measure of the relative valuation of the firm by the investment public, stocks with lower price-to-earnings multiples (that is, value stocks) are found to outperform stocks with higher price-to-earnings multiples (that is, growth stocks). The value anomaly is subsequently widely documented in international literature, casting doubt on the performance of highly priced growth stocks. The value anomaly is evident even when the actual historical sales growth is used as an indication of growth, instead of the price multiples suggested in the study conducted by Lakonishok, Shleifer and Vishny (1994).

The favoritism of value stocks in empirical literature raises the question as to whether the perceived future prospects of growth stocks are indeed overvalued by investors. Broussard, Michayluk and Neely (2005) argue that the superiority of value investing could be attributed to either the assertion that value stocks are riskier, or to the misspecification of growth manifested by investors. Nofsinger (2005) argues that investors often label good 
companies that have strong past performance as good investments without considering the sustainability of past performance and the cost of the investment. This argument implies that growth investors should be more disciplined with regard to the price they pay for the firms' future growth prospects. The concept of growth-at-a-reasonable-price (GARP) investment strategy is essentially a strategy that seeks for stocks that have above average earnings growth with average or below average price multiples.

This study attempts to draw comparisons between the performance of portfolios formed based on the pure growth selection criteria and portfolios formed based on the GARP selection criteria on the Taiwan Stock Exchange over the period from 01 January 2000 to 31 March 2010. The objective of this paper is to quantify the contributions of the GARP strategy to the improvements in portfolio returns, the reductions in portfolio risk and the overall improvements in the risk-adjusted performance compared to portfolios formed by the pure growth selection criteria. Seven attributes relating to the monthly sales growth of Taiwanese firms are identified. The sales-to-price ratio is used to measure the reasonableness of stock prices under the GARP selection criteria. The remainder of the paper first reviews the empirical debate between the value and the growth investment strategies. The data and methodology section discusses the details regarding the selection and formation of the pure growth portfolios and the GARP portfolios. The results section presents and analyzes the risk-return characteristics of the pre-specified portfolios. The conclusion section consolidates study results in comparison to findings of prior research.

\section{LITERATURE REVIEW}

Empirical studies generally classify stocks that have above average prices relative to their fundamental values as growth stocks. "The high market valuation accorded to growth stocks is puzzling at times, since high prices in excess of fundamental values indicate investors believe high growth rates are sustainable" (Broussard, Michayluk and Neely, 2005: 93). According to Broussard et al. (2005), companies operating in a growing industry are likely to entice competition in the market, increasing risk, thereby reducing future growth opportunities in the industry. Evidence on the success of growth investing is less encouraging compared to value investing that seeks for stocks with relatively lower price multiples.

\section{Value anomaly}

The evidence of outperformance for stocks with relatively lower price-to-earnings (P/E) ratios on the New York Stock Exchange (NYSE) is first discovered by Basu (1977) over the period from 1957 to 1971. Basu (1977) attributes the observed value anomaly to investor overreaction, which is in line with the argument of Benjamin Graham, the father of value investing, who stated in Graham and Dodd (1934) that the prices and the future potential of growth stocks are often exaggerated. Using the price-to-book value $(\mathrm{P} / \mathrm{B})$ ratio to classify growth and value stocks, Litzenberger and Ramaswamy (1979), Stattman (1980) and Bhandari (1988) also find stocks with relatively lower P/B ratios to outperform stocks with relatively higher P/B ratios. Fama and French (1992) attempt to explain the returns on the portfolios formed by different levels of P/B ratios using the capital asset pricing model (CAPM). It is found that the CAPM could not explain the abnormal returns earned by the value portfolios in the U.S. stock markets over the period from 1963 to 1990. By incorporating a value risk premium and a size risk premium, in addition to the market risk premium in the CAPM, Fama and French (1993) successfully explain the value anomaly. Fama and French (1993) conclude that value stocks earn higher returns due to higher risk. Lakonishok et al. (1994) examine the value effect on the NYSE and the American Stock Exchange (AMEX) using average 5-year sales growth rate in addition to the P/E, P/B and the price-to-cash flow $(\mathrm{P} / \mathrm{CF})$ ratios to classify growth stocks and value stocks. Significant positive value premiums are found for stocks with relatively lower historical sales growth and price multiples over the period from 1963 to 1990.

When tests of the value anomaly are extended to international economies, Fama and French (1998) discover a value premium for stocks with relatively lower P/E, P/B, P/CF ratios and higher dividend yields listed on NYSE, AMEX, NASDAQ and EAFE (Europe, Australia and Far East) over the period from 1975 to 1995. Similar results are found by Bauman, Conover and Miller (1998) on EAFE and the Canadian stocks over the period from 1986 to 1996. Chan and Lakonishok (2004) construct a composite value proxy using the P/E, P/B, P/CF and the price-to-sales (P/S) ratios of the stocks comprising the Morgan Stanley Capital International (MSCI) EAFE index. Evidence of a value premium is discovered over the period from 1989 to 2001 . Sheu, Wu and Ku (1998) examine 
the determinants of cross-sectional returns on the Taiwan Stock Exchange over the period from 1976 to 1996. Their study finds evidence of a value effect on the Taiwan Stock Exchange in that stocks with lower P/S ratios are likely to earn higher returns. Cheng, Lai and Tsai (2005) attempt to explain Taiwanese stock returns using the Fama and French (1993) 3-factor model over the period from 1982 to 2002. They find evidence of a weak value effect on the Taiwan Stock Exchange over the examination period.

\section{Growth investing and GARP}

The criticism of growth investing is primarily based on the so-called higgledy-piggledy patterns of earnings growth documented by Little (1962) and Lintner and Glauber (1967). These studies find evidence that future earnings growth rates are independent of past earnings growth rates. This observation implies that earnings growth follows a random walk and as a result future earnings growth cannot be forecasted.

Peters (1991) argues that price multiple measures are only appropriate for valuing mature firms that have steady business growth. By identifying firms that have significantly above-average long-term forecasts as growth stocks, Peters (1991) finds growth stocks to earn risk-adjusted abnormal returns over the period from 1982 to 1989. Broussard, Michayluk and Needy (2005) analyze the role of growth in long-term U.S. stock market returns over the period from 1981 to 1995 . Their study results indicate that the actual growth in earnings, sales and book values are primary valuation factors while the P/E and P/B ratios represent imperfect proxies for expected growth. They also find growth to be mean reverting and changes in growth rates tend to follow a random walk. Stewart, Neumann, Knittel and Heisler (2009) analyze the relationship between asset growth and abnormal returns for global stocks comprising the MSCI World Composite. Study results indicate that significant return predictive power of asset growth (2-year total asset growth in particular) is evident over the examination period from 1985 to 2009 when the size and $\mathrm{P} / \mathrm{B}$ factors are accounted for.

GARP investing is a disciplined growth investing approach rather than a new investment style (Trammell, 2006). Scott, Stumpp and Xu (1999) investigate the effects of behavioral biases in stock market valuation by analyzing the returns on the portfolios with different intersections between their respective earnings growth and P/E ratio rankings. Study results provide evidence of the merits for value investing over the period from 1989 to 1997. Although GARP investing represents the intersection of value and growth investing, portfolios formed by the intersection of high earnings growth and low $\mathrm{P} / \mathrm{E}$ ratios do not provide distinctive outperformance. Scott et al. (1999) suggest that GARP investors should focus on 'fallen angels' that are experiencing some evidence of a turnaround rather than cheap growing stocks. According to the Standard \& Poor's guide to selecting stocks, published in 2005, the primary screens for GARP stocks is the P/E-to-growth (PEG) ratio and GARP investors should avoid stocks with above average debt-to-equity ratio and below-average return-on-equity (ROE). These criteria prevent firms that are overpriced and firms that employ leverage to maintain high levels of growth to be included in the portfolio. Ahmed and Nanda (2001) argue that value and growth investing strategies should not be mutually exclusive. In particular, the actual growth in earnings is a better proxy for identifying growth stocks compared to the P/E ratio. Adopting a strategy that select stocks with low P/E ratio and high earnings growth (essentially a GARP investment strategy), Ahmed and Nanda (2001) find the new strategy to outperform the traditional low P/E investment strategy on a risk-adjusted basis over the period from 1982 to 1997.

Fama and French (2007) attempt to determine whether the primary source of returns of the value and growth portfolios is mainly attributable to the numerator or to the denominator of the $\mathrm{P} / \mathrm{B}$ ratio. The results reveal that while price reversals contribute significantly to the returns of the value portfolios, the returns of the growth portfolios are mainly driven by the growth in their book values over the period from 1926 to 2006. An investigation on the responsiveness of growth stocks and value stocks to earnings announcements conducted by Yan and Zhao (2011) reveal that value stocks respond more drastically to positive earnings surprises and are less sensitive to negative earnings surprises. Thus, growth investing could be subject to higher downside risk compared to value investing. The study results of Fama and French (2007) and Yan and Zhao (2011) imply that growth stocks are more likely to be overpriced compared to value stocks. O'Shaughnessy (2007) analyzes and compares the returns on the value and growth portfolios of 50 U.S. stocks over the period from 1963 to 2005. The growth portfolio with the highest historical 12 -month sales growth earned $-0.21 \%$ annualized returns while the value portfolio with the lowest $\mathrm{P} / \mathrm{E}, \mathrm{P} / \mathrm{CF}$ and $\mathrm{P} / \mathrm{S}$ ratios earned above $10 \%$ annualized returns over the examination period. "Growth factors on a 
stand-alone basis did not work nearly as well as value factors did because the typical growth company has a high $P / S$, a high price-to-book ratio, and a high price-to-cash-flow ratio - in other words, a high-expectations company. Investors have high hopes for growth companies, and when those high hopes are not met, stock's price can drop like a stone" (O’Shaughnessy, 2007: 14-15).

\section{DATA AND METHODOLOGY}

\section{Research sample}

All stocks listed on the Taiwan Stock Exchange over the period from 01 January 2000 to 31 March 2010 are included in the research database. To remove the survivorship bias, delisted stocks are included in the research database until the month of delisting. As of 31 March 2010, there are 763 stocks listed on the Taiwan Stock Exchange. To ensure that the sample stocks are established with ample liquidity, only the largest 200 stocks in terms of their market capitalizations at the beginning of each month are used as the research sample.

This research uses the actual sales growth rates as proxies for growth stocks. Seven sales attributes are computed for each of the 200 sample stocks at the beginning of each month over the examination period from 01 January 2000 to 31March 2010 (a total of 123 months). These attributes include year-on-year (YOY) monthly sales growth rate, monthly sales growth rate from previous month, monthly sales growth rate from historical high, monthly sales growth rate from historical low, YOY cumulative past 12-month sales growth rate, YOY cumulative past 3-month sales growth rate and cumulative past 3-month sales growth rate from previous month.

\section{Pure growth portfolios}

Three equally-weighted portfolios are constructed for each of the seven sales growth attributes by selecting the sample stocks with the highest 100,50 and 20 sales growth rates for the respective attributes at the beginning of each month. Thus, monthly rebalancing is required for the pure growth portfolios. The listed companies on the Taiwan Stock Exchange are required to publish monthly sales data by the $10^{\text {th }}$ day of the forthcoming calendar month. To effectively remove the look-ahead bias, the sales data of month $t-2$ are used to construct portfolios at the beginning of month $t$.

\section{GARP portfolios}

To construct growth-at-a-reasonable-price (GARP) portfolios, the top 100 stocks that have the lowest priceto-sales multiple are extracted from the 200 sample stocks at the beginning of each month over the examination period. The price-to-sales multiple is calculated as the current stock price divided by the latest available 12-month sales per share. Similarly, to avoid the look-ahead bias, the sum of monthly sales from month $t-13$ to month $t-2$ is used to estimate the latest available 12-month sales per share at the beginning of month $t$. Using the extracted 100 stocks as the base of stocks that are traded at a "reasonable price", the top 50 and 20 stocks are subsequently selected as the constituents for the GARP portfolios for each of the seven sales growth attributes.

\section{Evaluating the incremental contributions of GARP}

The pure growth portfolio of 100 constituents is used as the benchmark for each of the seven pure growth attributes. The pure growth portfolios of 50 and 20 constituents are more concentrated in terms of the underlying growth investment style compared to the benchmark portfolio of 100 constituents. Two conditions are required for the more concentrated portfolios to outperform the less concentrated portfolios: there must be an excess demand for stocks that possess the characteristic of the underlying pure growth attribute; the prices of these stocks are yet to reflect their growth potential at the time of portfolio formation. If the prices have been pushed equal to or above the "reasonable" level, it is unlikely that there will be abnormal payoffs to investors who seek for the particular growth attribute.

The proposed GARP methodology highlighted above first filters out stocks that trade at above-average price-to-sales multiples, and subsequently form portfolios of stocks that possess above-average growth potential in 
the pool. If the GARP methodology successfully prevents overpriced growth stocks being included in the portfolio, the more concentrated GARP portfolios of 50 and 20 constituents would outperform the pure growth portfolios of 50 and 20 constituents and the benchmark portfolio of 100 constituents.

The measures of incremental contributions of GARP include the additional returns, risk reductions and the additional risk-adjusted returns derived from the GARP portfolios compared to the pure growth portfolios of 50 and 20 constituents. The return of portfolio $X$ is computed in month $t$ using Equation 1:

$r_{X, t}=\sum_{i=1}^{N} r_{i, t} / N$

Where:

$r_{X, t} \quad$ is the return of portfolio $X$ in month $t$;

$r_{i, t} \quad$ is the return of the $i$ th constituent in portfolio $X$ in month $t$; and

$N \quad$ is the number of constituents in portfolio $X$.

Once the monthly portfolio returns are computed, the arithmetic average portfolio returns over the evaluation period of 123 months is computed using Equation 2, and annualized using Equation 3:

$R_{X}=\sum_{t=1}^{123} r_{X, t} / 123$

$R_{X \text { p.a. }}=\left(1+R_{X}\right)^{12}-1$

Portfolio risk is measured by the time-series standard deviation of the portfolio. The annualized standard deviation for portfolio $X$ over the evaluation period is computed using Equation 4:

$\sigma_{X \text { p.a. }}=\sqrt{\sum_{t=1}^{123}\left(r_{X, t}-R_{X} \text { p.a. }\right)^{2} / 122} \times \sqrt{12}$

Once the annualized portfolio returns and standard deviations are computed, the Sharpe ratios of the prespecified portfolios are computed using Equation 5 as their risk-adjusted returns:

$S R_{X, t}=\left(R_{X \text { p.a. }}-R_{f \text { p.a }}\right) / \sigma_{X \text { p.a. }}$

The annualized return for the risk-free asset, $R_{f \text { p.a. }}$ in Equation 5, is proxied by the returns on the 90-day treasury securities provided by the Taiwan Stock Exchange. On the other hand, the market portfolio is proxied by the equally-weighted portfolio of the 200 sample stocks in the database.

\section{RESULTS}

\section{Performance of the pre-specified portfolios against the market proxy}

The comparison of the risk-return characteristics of the pure growth portfolios and the GARP portfolios is displayed in Table 1. Panel (a) to Panel (g) of Table 1 demonstrate the details of the portfolio performance for the seven growth proxies respectively. The incremental GARP contributions in terms of the improvements in portfolio returns, reductions in portfolio risk and the improvements in the Sharpe ratio are presented in the last column in Table 1. Over the 123-month evaluation period, the market proxy has achieved an annualized return of $3.86 \%$ and an annualized standard deviation of $26.81 \%$ (refer to the note of Table 1). All of the pure growth portfolios and the GARP portfolios earn much higher returns with substantially higher standard deviations compared to the market proxy. Using the Sharpe ratio to measure the excess return per unit of risk, it is apparent that all pure growth portfolios and GARP portfolios outperform the market proxy on a risk-adjusted basis. This result indicates that growth is a major factor that drives stock market performance on the Taiwan Stock Exchange. 


\section{Performance of the pure growth portfolios}

With the exception of portfolios from the (a) YOY monthly sales growth rate and (c) monthly sales growth rate from historical high categories, the pure growth portfolios do not exhibit consistent improvements in returns when the portfolios become more concentrated in their underlying growth investment styles, despite the consistent increases in portfolio risk. An examination of the Sharpe ratios of the pure growth portfolios reveals that (c) monthly sales growth rate from historical high is the only category under which the Sharpe ratio improves consistently when the portfolios become more concentrated. Portfolios formed by growth attributes such as (b) monthly sales growth rate from previous month and (d) monthly sales growth rate from historical low actually exhibit deteriorations in their Sharpe ratios when the portfolios become more concentrated in their growth investment styles. Overall, the portfolios in the (a) YOY monthly sales growth rate and (c) monthly sales growth rate from historical high categories outperform the portfolios from other categories on a risk-adjusted basis.

\section{Incremental contribution of GARP}

All GARP portfolios outperform the comparable pure growth portfolios on a risk-adjusted basis. The GARP portfolios earn considerably higher returns compared to the pure growth portfolios. A consistent improvement in the risk-adjusted performance is observed when the GARP portfolios become more concentrated in their underlying investment styles. There is also a substantial reduction in the portfolio standard deviations. This observation suggests that blindly chasing after growth stocks without taking into account their prices introduces substantial risk to the portfolio. Overpriced growth stocks are potentially riskier and less resilient in market downturns during the corrections of their long-term fundamental means. The most substantial contribution of GARP is observed for portfolios under the (b) monthly sales growth rate from previous month and (d) monthly sales growth rate from historical low. As noted above, portfolios formed by these two growth attributes also experience declining Sharpe ratios when the portfolios become more concentrated. The Sharpe ratios for the portfolios of 50 and 20 stocks improve from $7.08 \%$ and $5.38 \%$ to $21.61 \%$ and $25.36 \%$, respectively, when the selection method is switched from the pure growth technique to the GARP technique. Even the portfolios from the top-performing categories, such as category (a) YOY monthly sales growth rate and category (c) monthly sales growth rate from historical high improve notably in their risk-adjusted performance when the GARP selection technique is employed. For category (a) YOY monthly sales growth rate, the Sharpe ratios for the portfolios of 50 and 20 stocks improve from $23.79 \%$ and $30.72 \%$ to $40.34 \%$ and $45.09 \%$, respectively, when the GARP selection method is used. On the other hand, the Sharpe ratios for the portfolios of 50 and 20 stocks under category (c) monthly sales growth rate from historical high improve from $27.43 \%$ and $35.22 \%$ to $38.15 \%$ and $46.94 \%$ respectively when the GARP selection method is used. The incremental contributions of GARP to Sharpe ratios for the portfolios in the seven growth categories over the examination period are demonstrated in panel (a) to panel (g) of Figure 1. The black bars represent the Sharpe ratios of the portfolios formed by the pure growth attributes. The incremental contributions to the Sharpe ratios are represented by the grey bars on top of the black bars. The first black bar in each of the seven growth categories represents the Sharpe ratio for the benchmark portfolio of 100 stocks formed by the underlying pure growth attribute. Once the stocks with above-average price-to-sales ratio are filtered out, considerable improvements in the Sharpe ratios for the pre-specified portfolios are observed for each growth category. This finding suggests that the potentials for the stocks with historically high sales growth are often overrated by investors.

An interesting observation is that the improvements in Sharpe ratios are greater for the portfolios of 50 stocks compared to the portfolios of 20 stocks. Despite category (a) YOY monthly sales growth rate and (c) monthly sales growth rate from historical high, the Sharpe ratios for the GARP portfolios of 50 stocks and the GARP portfolios of 20 stocks are not distinguishable. There is not much incremental benefit for investors to move from the GARP portfolios of 50 stocks to more concentrated GARP portfolios of 20 stocks. An examination of the risk-return characteristics of the GARP portfolios indicate that the GARP portfolios of 20 stocks generally have both higher returns and higher standard deviations compared to the GARP portfolios of 50 stocks in the same category. An explanation for this phenomenon is less likely to relate to mispricing since the GARP stocks have average or belowaverage price-to-sales ratios. The more likely explanation for the lack of improvement in the Sharpe ratios of more concentrated GARP portfolios is that the stocks that exhibit the highest historical sales growth have potentially higher risks compared to the stocks with moderately high sales growth. 


\begin{tabular}{|c|c|c|c|c|c|c|c|c|}
\hline \multirow[b]{3}{*}{ Portfolio Size } & \multirow[b]{3}{*}{ : } & (a) & \multicolumn{6}{|c|}{ Year-On-Year (YOY) Monthly Sales Growth Rate } \\
\hline & & \multicolumn{3}{|c|}{ Pure Growth Portfolios } & \multicolumn{2}{|c|}{ GARP Portfolios } & \multicolumn{2}{|c|}{ GARP Contribution } \\
\hline & & 100 & 50 & 20 & & 20 & 50 & 20 \\
\hline Return p.a. & : & $10.29 \%$ & $10.72 \%$ & $14.15 \%$ & $14.80 \%$ & $17.37 \%$ & $4.08 \%$ & $3.22 \%$ \\
\hline Std. Deviation p.a. & : & $30.92 \%$ & $33.78 \%$ & $37.32 \%$ & $30.05 \%$ & $32.56 \%$ & $-3.73 \%$ & $-4.76 \%$ \\
\hline \multirow[t]{3}{*}{ Sharpe Ratio } & $:$ & $24.62 \%$ & $23.79 \%$ & $30.72 \%$ & $40.34 \%$ & $45.09 \%$ & $16.55 \%$ & $14.37 \%$ \\
\hline & & (b) & \multicolumn{6}{|c|}{ Monthly Sales Growth Rate from Previous Month } \\
\hline & & \multicolumn{3}{|c|}{ Pure Growth Portfolios } & \multicolumn{2}{|c|}{ GARP Portfolios } & \multicolumn{2}{|c|}{ GARP Contribution } \\
\hline Portfolio Size & : & 100 & 50 & 20 & & 20 & 50 & 20 \\
\hline Return p.a. & : & $7.68 \%$ & $7.02 \%$ & $4.94 \%$ & $11.13 \%$ & $11.21 \%$ & $4.11 \%$ & $6.27 \%$ \\
\hline Std. Deviation p.a. & : & $30.91 \%$ & $33.54 \%$ & $35.40 \%$ & $31.22 \%$ & $33.87 \%$ & $-2.32 \%$ & $-1.53 \%$ \\
\hline \multirow[t]{3}{*}{ Sharpe Ratio } & $:$ & $16.17 \%$ & $12.93 \%$ & $6.38 \%$ & $27.05 \%$ & $25.17 \%$ & $14.12 \%$ & $18.79 \%$ \\
\hline & & (c) & \multicolumn{6}{|c|}{ Monthly Sales Growth Rate from Historical High } \\
\hline & & \multicolumn{3}{|c|}{ Pure Growth Portfolios } & \multicolumn{2}{|c|}{ GARP Portfolios } & \multicolumn{2}{|c|}{ GARP Contribution } \\
\hline Portfolio Size & : & 100 & 50 & 20 & 50 & 20 & 50 & 20 \\
\hline Return p.a. & : & $9.64 \%$ & $10.92 \%$ & $14.52 \%$ & $13.90 \%$ & $17.40 \%$ & $4.11 \%$ & $2.88 \%$ \\
\hline Std. Deviation p.a. & : & $28.38 \%$ & $30.02 \%$ & $33.60 \%$ & $29.40 \%$ & $31.35 \%$ & $-0.62 \%$ & $-2.25 \%$ \\
\hline \multirow[t]{3}{*}{ Sharpe Ratio } & : & $24.53 \%$ & $27.43 \%$ & $35.22 \%$ & $38.15 \%$ & $46.94 \%$ & $10.72 \%$ & $11.72 \%$ \\
\hline & & (d) & \multicolumn{6}{|c|}{ Monthly Sales Growth Rate from Historical Low } \\
\hline & & \multicolumn{3}{|c|}{ Pure Growth Portfolios } & \multicolumn{2}{|c|}{ GARP Portfolios } & \multicolumn{2}{|c|}{ GARP Contribution } \\
\hline Portfolio Size & : & 100 & 50 & 20 & 50 & 20 & 50 & 20 \\
\hline Return p.a. & : & $7.80 \%$ & $5.03 \%$ & $4.47 \%$ & $12.04 \%$ & $11.21 \%$ & $7.01 \%$ & $6.74 \%$ \\
\hline Std. Deviation p.a. & $:$ & $32.95 \%$ & $33.14 \%$ & $33.29 \%$ & $32.63 \%$ & $32.95 \%$ & $-0.51 \%$ & $-0.34 \%$ \\
\hline Sharpe Ratio & : & $15.54 \%$ & $7.08 \%$ & $5.38 \%$ & $28.69 \%$ & $30.74 \%$ & $21.61 \%$ & $25.36 \%$ \\
\hline
\end{tabular}

(e) Year-On-Year (YOY) Cumulative Past 12-Month Sales Growth Rate

\begin{tabular}{|c|c|c|c|c|c|c|c|}
\hline \multirow[b]{2}{*}{ Portfolio Size } & \multicolumn{3}{|c|}{ Pure Growth Portfolios } & \multicolumn{2}{|c|}{ GARP Portfolios } & \multicolumn{2}{|c|}{ GARP Contribution } \\
\hline & $\overline{100}$ & 50 & 20 & 50 & 20 & 50 & 20 \\
\hline Return p.a. & $7.68 \%$ & $7.65 \%$ & $10.34 \%$ & $11.67 \%$ & $12.03 \%$ & $4.02 \%$ & $1.69 \%$ \\
\hline Std. Deviation p.a. & $31.53 \%$ & $33.90 \%$ & $36.80 \%$ & $31.40 \%$ & $33.18 \%$ & $-2.50 \%$ & $-3.62 \%$ \\
\hline Sharpe Ratio & $15.84 \%$ & $14.67 \%$ & $20.82 \%$ & $28.64 \%$ & $28.17 \%$ & $13.97 \%$ & $7.35 \%$ \\
\hline
\end{tabular}

(f) Year-On-Year (YOY) Cumulative Past 3-Month Sales Growth Rate

\begin{tabular}{|c|c|c|c|c|c|c|c|}
\hline & \multicolumn{3}{|c|}{ Pure Growth Portfolios } & \multicolumn{2}{|c|}{ GARP Portfolios } & \multicolumn{2}{|c|}{ GARP Contribution } \\
\hline Portfolio Size & 100 & 50 & 20 & 50 & 20 & 50 & 20 \\
\hline Return p.a. & $9.94 \%$ & $9.39 \%$ & $15.61 \%$ & $15.62 \%$ & $16.59 \%$ & $6.23 \%$ & $0.98 \%$ \\
\hline Std. Deviation p.a. & $31.04 \%$ & $34.00 \%$ & $37.98 \%$ & $30.34 \%$ & $32.60 \%$ & $-3.66 \%$ & $-5.38 \%$ \\
\hline Sharpe Ratio & $23.38 \%$ & $19.74 \%$ & $34.04 \%$ & $42.64 \%$ & $42.66 \%$ & $22.90 \%$ & $8.62 \%$ \\
\hline
\end{tabular}

(g) Cumulative 3-Month Sales Growth Rate from Previous Month

\begin{tabular}{|c|c|c|c|c|c|c|c|c|}
\hline \multirow[b]{2}{*}{ Portfolio Size } & & \multicolumn{3}{|c|}{ Pure Growth Portfolios } & \multicolumn{2}{|c|}{ GARP Portfolios } & \multicolumn{2}{|c|}{ GARP Contribution } \\
\hline & : & 100 & 50 & 20 & 50 & 20 & 50 & 20 \\
\hline Return p.a. & : & $8.36 \%$ & $7.55 \%$ & $7.82 \%$ & $11.05 \%$ & $11.98 \%$ & $3.50 \%$ & $4.16 \%$ \\
\hline Std. Deviation p.a. & : & $30.81 \%$ & $33.98 \%$ & $35.99 \%$ & $30.74 \%$ & $34.60 \%$ & $-3.24 \%$ & $-1.39 \%$ \\
\hline Sharpe Ratio & : & $18.42 \%$ & $14.32 \%$ & $14.28 \%$ & $27.22 \%$ & $26.87 \%$ & $12.90 \%$ & $12.59 \%$ \\
\hline
\end{tabular}


(a) Year-On-Year (YOY) Monthly Sales Growth Rate

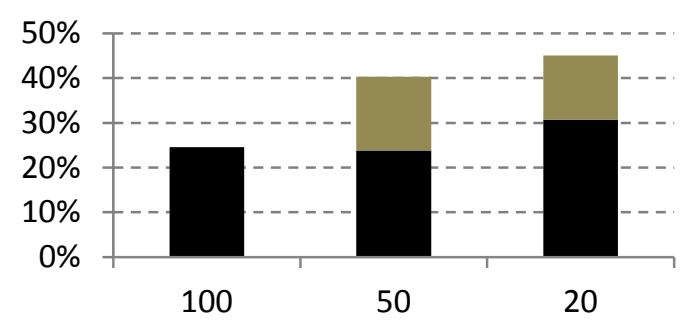

(c) Monthly Sales Growth Rate from Historical High

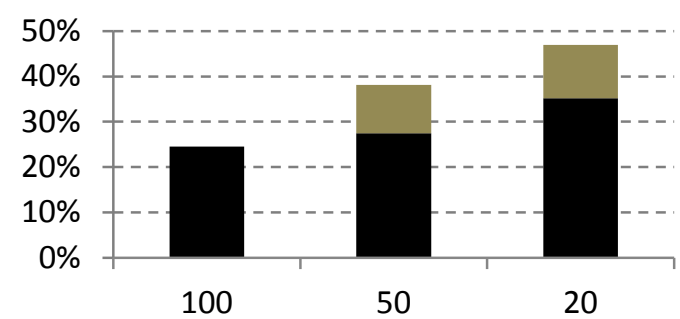

(e) YOY Cumulative Past 12-Month Sales Growth Rate

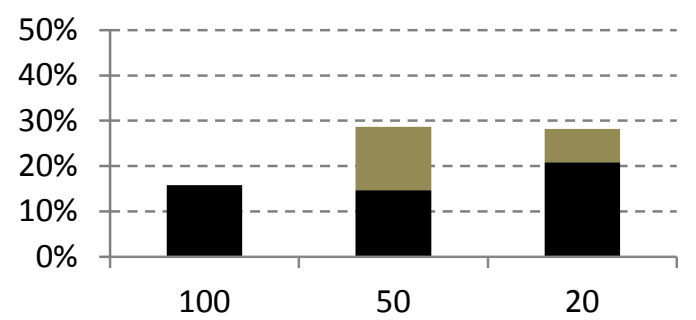

(b) Monthly Sales Growth Rate from Previous Month

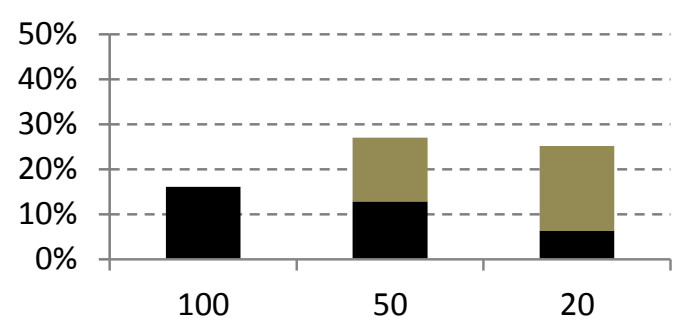

(d) Monthly Sales Growth Rate from Historical Low

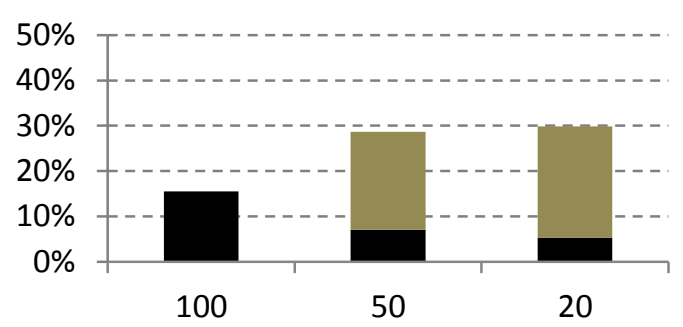

(f) YOY Cumulative Past 3-Month Sales Growth Rate

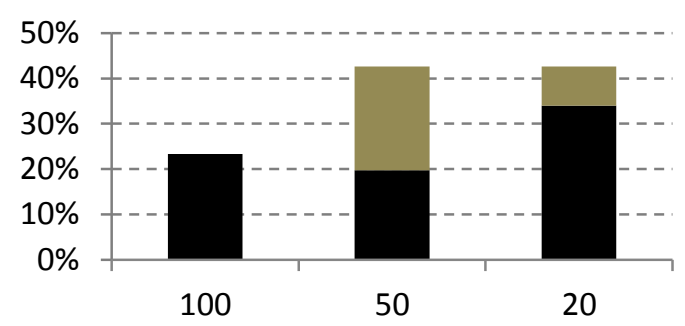

(g) Cumulative 3-Month Sales Growth Rate from Previous Month

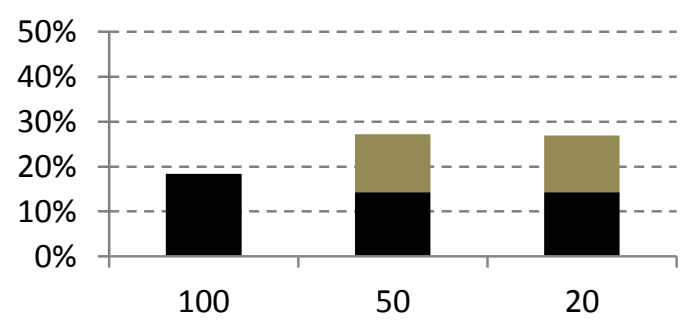

Figure 1: Incremental Contribution of GARP to Sharpe Ratio: 01/01/2000 to 31/03/2010 


\section{CONCLUSION}

Empirical literature on value investing versus growth investing generally finds value investing to be a favorable long-term investment strategy. In addition to the higgledy-piggledy phenomenon regarding successive earnings growth, many prior studies find growth stocks to be overpriced and are potentially riskier when the high expectations of investors are not met. Researchers also argue that the actual growth in earnings, sales and assets are better indications of the stocks' growth potential and that price multiples are poor measures of firms in growing industries. Although value investing and growth investing are often perceived as opposite investment styles, it is also argued that these two investment strategies should not be mutually exclusive. The growth-at-a-reasonable price (GARP) investment strategy is essentially a disciplined growth investing technique that enables investors to avoid paying unreasonable prices for future growth that, to a large degree, is uncertain.

In this study, we identify seven growth attributes that are based on the actual growth in monthly sales relative to previous month, year, historical high and historical low, in order to determine the growth potentials of stocks listed on the Taiwan Stock Exchange. Pure growth portfolios of 100, 50 and 20 stocks are formed and rebalanced monthly for each of the seven pre-specified growth attributes over the examination period from 01 January 2000 to 31 March 2010. On the other hand, GARP portfolios of 50 and 20 stocks are formed by first selecting the 100 stocks that have average or below-average price-to-sales (P/S) ratios, and subsequently selecting 50 and 20 stocks with the highest growth attributes from these 100 stocks at the beginning of each month.

The GARP selection criteria ensure that the growth stocks in the portfolios are not overpriced as they trade at reasonable P/S ratios. Study results reveal that although the pure growth portfolios outperform the market proxy on a risk-adjusted basis, their Sharpe ratios fail to improve when the portfolios become more concentrated as higher returns for the more concentrated portfolios are achieved at the expense of higher risk. By removing the stocks that are traded at an above-average P/S multiple, the GARP portfolios outperform their otherwise identical pure growth portfolios on a risk-adjusted basis. The GARP selection technique contributes to the existing investment strategy in improving returns, reducing risk and improving the risk-adjusted returns. However, the improvements in the Sharpe ratios are greater for the portfolios of 50 stocks compared to the portfolios of 20 stocks. The Sharpe ratios for the GARP portfolios of 50 stocks and the GARP portfolios of 20 stocks are not distinguishable. An examination of the risk-return characteristics of the GARP portfolios indicate that the GARP portfolios of 20 stocks generally have both higher returns and higher standard deviations compared to the GARP portfolios of 50 stocks. This implies that the stocks with the highest prior sales growth are potentially riskier compared to the stocks with moderately high sales growth.

\section{ACKNOWLEDGEMENTS}

This work is supported by the National Research Foundation (NRF) of South Africa. We wish to thank the Research Office and the School of Business and Finance of the University of the Western Cape for their support.

\section{AUTHOR INFORMATION}

Dr. Kathleen Hodnett is currently a Research Fellow (funded by the National Research Foundation (NRF) of South Africa) and Senior Lecturer in the School of Business and Finance at the University of the Western Cape, South Africa. She is a member of the International Institute of Forecasters (IIF) and an associate of the South African Institute of Financial Markets (SAIFM).

Dr. Heng-Hsing Hsieh, CFA is the Head of Finance in the School of Business and Finance at the University of the Western Cape, South Africa. He is a CFA charterholder and a member of the South African Institute of Financial Markets (SAIFM). E-mail: ahsieh@uwc.ac.za (Corresponding author) 


\section{REFERENCES}

1. Ahmed P. and Nanda S. (2001), "Style Investing: Incorporating Growth Characteristics in Value Stocks", Journal of Portfolio Management, vol. 27, no. 3, 47-59.

2. Basu S. (1977), "The Investment Performance of Common Stocks in Relation to Their Price-to-Earnings Ratio: A Test of the Efficient Market Hypothesis", Journal of Finance, vol. 12, no. 1, 129-156.

3. Bhandari L. C. (1988), "Debt-Equity Ratio and Expected Common Stock Returns", Journal of Finance, vol. 43, no. 2, 507-528.

4. Broussard J. P., Michayluk D. and Neely W. P. (2005), "The Role of Growth in Long Term Investment Returns", The Journal of Applied Business Research, vol. 21, no. 1, 93-104.

5. Chan L. K. C. and Lakonishok J. (2004), "Value and Growth Investing: Review and Update", Financial Analysts Journal, vol. 60, no. 1, 71-86.

6. Cheng T., Lai H. and Tsai P (2005), "On the Two-Stage Estimation of Fama-French Three Factor Models: Evidence from Taiwan", Working Paper.

7. Fama E. F. and French K. R. (1992), "The Cross-Section of Expected Stock Returns", Journal of Finance, vol. 47, 427-465.

8. Fama E. F. and French K. R. (1993), "Common Risk Factors in the Returns on Stocks and Bonds", Journal of Financial Economics, vol. 33, no. 1, 3-56.

9. Fama E. F. and French K. R. (1998), "Value Versus Growth: The International Evidence”, Journal of Finance, vol. 53, no. 6, 1975-1999.

10. Fama E. F. and French K. R. (2007), "The Anatomy of Value and Growth Stock Returns", Financial Analysts Journal, vol. 63, no. 6, 44-54.

11. Graham B. and Dodd D. (1934), "Security Analysis", McGraw Hill, New York.

12. Hamman W.D., Jordaan A.C. and Smit E. v.d. M. (1995), "Earnings Changes: A Random Walk? Some South African Evidence", Investment Analysts Journal, no. 41, 49-56.

13. Kaye M. (2005), "Standard \& Poor's Guide to Selecting Stocks", McGraw-Hill.

14. Lakonishok J., Shleifer A. and Vishny R. W. (1994), "Contrarian Investment, Extrapolation and Risk", Journal of Finance, vol. 49, no. 5, 1541-1578.

15. Li X., Becker Y and Rosenfeld D. (2012), “Asset Growth and Future Stock Returns: International Evidence”, Financial Analysts Journal, vol. 68, no. 3, 51-62.

16. Lintner J. and Glauber R. (1967), "Higgledy Piggledy Growth in America", Seminar on the Analysis of Security Prices, University of Chicago.

17. Little I. M. D. (1962), "Higgledy Piggledy Growth", Bulletin of the Oxford Institute of Economics and Statistics, vol. 24, 387-412.

18. Litzenberger R. and Ramaswamy K. (1979), "The Effects of Personal Taxes and Dividends on Capital Asset Prices: Theory and Empirical Evidence", Journal of Financial Economics, vol. 7: 163-195.

19. Nofsinger J. R. (2005), "The Psychology of Investing”, Prentice Hall, third edition.

20. O'Shaughnessy J.P. (2007), “Expected Rates of Return: Back to the Future?”, CFA Conference Proceedings Quarterly, June, vol. 24, no. 2, 13-24.

21. Peters D. (1991), "Valuing a Growth Stock", Journal of Portfolio Management, vol. 17, no. 3, 49-51.

22. Scott J, Stumpp M and Xu P. (1999), "Behavioral Bias, Valuation, and Active Management", Financial Analysts Journal, vol. 55, no. 4, 49-57.

23. Sheu H., Wu S. and Ku K. (1998), "Cross-Sectional Relationships between Stock Returns and Market Beta, Trading Volume, and Sales-to-Price in Taiwan”, International Review of Financial Analysis, vol. 7, no. 1, $1-18$.

24. Stattman D. (1980), "Book Values and Expected Stock Returns”, Unpublished MBA Dissertation, University of Chicago, Illinois.

25. Stewart S. D., Neumann J. J., Knittel C. R. and Heisler J. (2009), “Absence of Value: An Analysis of Investment Allocation Decisions by Institutional Plan Sponsors", Financial Analysts Journal, vol. 65, no. 6, 34-51.

26. Trammell S. (2006), "Is It Time to Tilt the Portfolio toward Growth and Away from Value or Vice Versa?", CFA Magazine, May/June, 37-41.

27. Yan Z. and Zhao Y. (2011). "When Two Anomalies Meet: the Post-Earnings Announcement Drift and the Value-Glamour Anomaly", Financial Analysts Journal, vol. 67, no. 6, 46-60. 